Patricia M. Davies

\section{Steps to Follow: The Comprehensive Treatment of Patients with Hemiplegia, ed 2}

\author{
Springer, Berlin 2000 \\ 514 pp.; DEM 98.-
}

ISBN 3-540-60720-X

It is a great pleasure to read the updated book of this talented and well-known physiotherapist. In this fascinating, scrupulously researched and useful textbook, Pat Davies develops the current knowledge in the field of rehabilitation of hemiplegic patients. Based on Bobath's concept, she offers us her own professional experience. Compared with the first edition, she includes valuable new activities.

The book is divided into 16 main chapters. In the first one, the author develops her concept of neurorehabilitation. She insists on the fact that failure to learn or to improve daily activities can be the result of perceptual problems and not only due to motor deficit. In fact, in the presence of a perceptual deficit, the hemiplegic patient will fail to adapt correctly in his daily life.

According to Pat Davies, the aim of physiotherapy is that the patient learns in contact with his environment, in real-life situations. All the therapy must be then task orientated, and the therapist must guide the patient's gesture during the performance of real life. The concept of guide movement therapy (guiding) is clearly explained. It is illustrated by many photographs, and it gathers many advice to chose the right goal and objective of rehabilitation. The second chapter, also wealthily illustrated, explains the normal movement sequences and balance reactions. Immediately, the clinician will realize how much the conventional neurological examination minimizes these aspects. This is more evident with the reading of the next chapter devoted to abnormal movement patterns in hemiplegia. Again excellent photographs demonstrate how body positions can reveal spasticity which could have been missed during a conventional neurological examination. This clinical introduction is clearly comprehensive, and all, specific aspects of assessment are highlighted by different photographs.

Then the reader enters the most important part of this book and discovers a concise but really comprehensive teaching of reeducating functional patients to obtain maximal indepndence in activities of daily living. Each chapter is not only well presented, but every aspect of each motor function is developed. The author does not only limit a teaching to Bobath's techniques, but clearly explains how to interpret this technique into rehabilitation.

In the third part, special attention is addressed to typical problems of hemiplegics, such as shoulder or face problems and the 'pusher syndrome'. The chapter devoted to shoulder problems is wealthily illustrated and contains a lot of advice to avoid such a painful complication.

Thus this is a very comprehensive book designed for physiotherapists and is also recommended for neurologists or physicians familiar with hemiplegic patients. It can serve both as a guide for understanding Bobath's concept of neurorehabilitation and as a textbook containing in-depth discussions of the management of hemiplegic patients. It ought to be in every medical library of people interested in neurorehabilitation.

Dr. P. Vuadens, Sion

\section{S. Silberstein, R. Lipton, D. Dalessio (eds)}

\section{Wolff's Headache and Other Head Pain, ed 7}

\section{Oxford University Press, Oxford 2001}

Wolff's Headache is the headache bible in the United States. Wolff was the first famous headache researcher and clinician in the US and published the first edition in 1948. The first edition was written exclusively by himself. Wolff died in 1962 shortly after completing the second edition. The seventh edition is edited by Stephen Silberstein from the Jefferson Headache Clinic in Philadelphia, Richard Lipton from the Albert Einstein College of Medicine in New York and the long-time editor of earlier editions, Donald Dalessio. In contrast to earlier editions, authors now come from all over the world and not only from the United States. As the title implies, the topic is not only migraine but all primary and secondary headaches. New chapters deal with the genetics of headache disorders and communication with the patient. It is impressive how up-to-date the book is. References are included until the first half of the year 2000. The book has around 600 pages and therefore can be read in 1 or 2 weeks. In my collection of headache books from all around the world this edition ranks within the top 5. It reflects a good mixture of science and basic research with translation into clinical practice. The editors selected authors with a vast practical experience in diagnosing treating headache patients. I can only recommend the book to any physician interested in headache.

H.C. Diener, Essen

\section{KARGER}

(C) 2002 S. Karger AG, Basel

Fax + 41613061234

E-Mail karger@karger.ch

www.karger.com
Accessible online at

www. karger.com/journals/ene 
Randolph W. Evans, Ninan T. Mathew

\section{Handbook of Headache}

Lippincott, Williams \& Wilkins, New York 2000 339 pp., USD 37.95

ISBN 0-7817-1877-5

This is a new concise and detailed handbook of headaches written by two experts in this field. The book begins with the problem of the diagnosis of headaches before going on to descriptions of migraine, tension-type, chronic daily, cluster, first or worst and posttraumatic headaches. Chapters follow on headaches during childhood, headaches in women and people over the age of 50, short-lasting head pains, vascular disorders, neoplasms, high and low intracranial pressure, head, ear, nose, and throat disorders and other secondary headaches. The last chapters are devoted to discussions of 39 cases of common and uncommon headaches and questions and answers about the main types of headaches. At the end, the authors briefly describe the alternative treatments of headaches.

Each chapter contains useful tables and essential references. This book gives quick access to principal facts for diagnosis and treatments of headaches through a very complete subject index. The handbook of headache will serve as a reliable and comprehensive resource for general practitioners and also for neurologists.

J. Bogousslavsky, Lausanne

\section{J.F. Toole}

\section{Cerebrovascular Disorders, ed 5}

Lippincott, Williams \& Wilkins, New York 2001

In the historic times of neurology, textbooks were written by a single author. Today multiauthor books are the standard. James F. Toole, the Walter C. Teagle Professor of Neurology at Wake Forest University, Winston-Salem, North Carolina, President of the World Federation of Neurology and President-elect of the International Stroke Society, has written all five editions of his book himself. Only small parts are authored by specialists. The book covers all aspects of stroke: transient ischemic attacks, brain infarction, hemorrhage and subarachnoidal hemorrhage. All rare and uncommon causes of stroke such as inflammatory angiopathies and arteriopathies are covered. Separate chapters deal with diagnostic procedures. Therapies are discussed in the context of particular diseases. What I like in particular is that references are not put in the text (and do not disturb the flow of reading) but are arranged in topical order at the end of each chapter. I bought all editions of this book, used them all for my clinical work, teaching and writing and will do so with this edition. Cerebrovascular Disorders is a highlight in medical writing.

H.C. Diener, Essen 